DOI: https://doi.org/10.36910/6775-2524-0560-2020-41-12

УДК 004.048

Мартиненко Андрій Анатолійович, старший викладач, аспірант.

https://orcid.org/0000-0002-5033-4696

Мороз Борис Іванович, д.т.н., професор.

http://orcid.org/0000-0002-5625-0864

Гуліна Ірина Григорівна, к.т.н., доцент.

https://orcid.org/0000-0003-2565-5006

Національний технічний університет «Дніпровська політехніка», м. Дніпро, Україна.

\title{
ІНСТРУМЕНТИ ПОБУДОВИ ІНТЕЛЕКТУАЛЬНОЇ СИСТЕМИ ПІДТРИМКИ ПРИЙНЯТТЯ РІШЕНЬ ІДЕНТИФІКАЦІї КУЛЬТУРНИХ ЦННОСТЕЙ
}

Мартиненко А.А., Мороз Б.І., Гуліна І.Г. Інструменти побудови інтелектуальної системи підтримки прийняття рішень ідентифікації культурних цінностей. У статті розглядається проблема розробки інтелектуальної системи підтримки прийняття рішень ідентифікації культурних цінностей, питання вибору і обгрунтування методів та інструментів для іï побудови. Розглянуто методи дослідження та побудови складних об'єктів, перспективи використання сучасних штучних нейронних мереж як інструменту для розробки інтелектуальної системи підтримки прийняття рішень. Також визначено перспективи та шляхи подальшого дослідження і використання даної предметної області.

Ключові слова: система підтримки прийняття рішень, інтелектуальний аналіз даних, ідентифікація культурних цінностей, нейронні мережі.

Мартыненко А.А., Мороз Б.И., Гулина И.Г. Инструменты построения интеллектуальной системы поддержки принятия решений идентификации культурных ценностей. В статье рассматривается проблема разработки интеллектуальной системы поддержки принятия решений идентификации культурных ценностей, вопросы выбора и обоснования методов и инструментов для ее построения. Рассмотрены методы исследования и построения сложных объектов, перспективы использования современных искусственных нейронных сетей как инструмента для разработки интеллектуальной системы поддержки принятия решений. Также определены перспективы и пути дальнейшего исследования и использования данной предметной области.

Ключевые слова: система поддержки принятия решений, интеллектуальный анализ данных, идентификация культурных ценностей, нейронные сети.

A. Martynenko, B. Moroz, I. Hulina. Building tools of an intelligent decision support system to identify cultural values. The article discusses the problem of developing an intelligent decision support system for identifying cultural values, the issues of choosing and justifying methods and tools for its construction. The methods of research and construction of complex objects, the prospects of using modern artificial neural networks as a tool for the development of an intelligent decision support system are considered. The prospects and ways of further research and use of this subject area are also identified.

Keywords: decision support system, data mining, identification of cultural values, neural networks.

Вступ. Постановка проблеми. У роботах [1-3] авторами була запропонована і описана загальна схема інтелектуальної системи підтримки прийняття рішень (ICППР) для ідентифікації культурних цінностей (КЦ). У запропонованій авторами схемі можна виділити кілька груп елементів наведеної структури: зберігання інформації; системи забезпечення інтерфейсами користувача i системи і власне головний елемент системи - підсистема, що забезпечує обробку і аналіз інформації для отримання відповіді-рішення про ідентифікацію об'єкта КЦ. Даний елемент фактично являє собою структуру (модель), яка дозволяє перетворити ідентифікаційні ознаки об’єкту в аналітичні матеріали (довідки), які можуть служити користувачеві для підтримки прийнятого рішення. Основною ідеєю, яка розглядається авторами в даній роботі, $є$ аналіз і обгрунтування вибору інструментарію для побудови сучасних ІСППР. Особливу увагу приділяється саме методам та засобам організації підсистеми обробки і аналізу інформації для отримання відповіді-рішення ІСППР.

Аналіз досліджень. Як зазначається в роботі [4], в даний час набули поширення ряд методів дослідження і побудови складних об'єктів, до яких відносяться і ІСППР. До таких методів належать: нейронні мережі (НМ), метод групового урахування аргументів (МГУА), еволюційне моделювання (генетичні алгоритми), регресійний аналіз і т.п. Слід зазначити, що перераховані методи мають як ряд переваг так і свої недоліки.

Також слід зазначити, що ряд сучасних ІСППР побудовані на використанні експертних систем (EC), знань експертів, теорії розмитих (нечітких) множин та ін.

Оцінка якості прийняття рішення (відповіді системи на запит користувача) в таких системах, побудованих на ймовірнісних методах, не завжди задовольняють заданим параметрам точності, тому слід приділити увагу альтернативним методам. 
В даний час, з розвитком теорії штучних нейронних мереж (ШНМ), на думку авторів, з'явилася можливість більш точного вирішення задачі ідентифікації КЦ в порівнянні з пропонованими раніше методами [5-7].

Мета дослідження. Підвищення якості та ефективності рішення практичної задачі створення ІСППР за використання сучасних інструментів, методів та засобів, що мають ряд переваг в порівнянні з пропонованими раніше.

Виклад основного матеріалу й обгрунтування отриманих результатів дослідження. За останні роки великої популярності набрало використання такого потужного інструменту як нейронні мережі. При чому використання НМ може бути застосовано для розпізнавання, ідентифікації об'єктів КЦ так і при побудові самої ІСППР, оскільки ії можна розглядати як клас методів моделювання.

Сучасні нейронні мережі використовуються для вирішення складних обчислювальних i аналітичних задач [8]. Такими задачами та галузями застосування можуть бути:

- Розпізнавання образів. Даний тип задач може бути використано при роботі підсистеми розпізнавання об'єктів КЦ.

- Класифікація - розподіл даних за параметрами (ознаками). Даний тип задач може бути використано при роботі підсистеми формування сховища даних.

- Прийняття рішень і управління. Даний тип задач може бути використано при роботі підсистеми саме формування запитів користувача до системи і НМ та формування довідок-відповідей.

- Кластеризація. Даний тип задач також може бути використано при роботі підсистеми формування запитів користувача до системи і НМ та формування довідок-відповідей, в умовах коли $\epsilon$ необхідність розбиття множини вхідних сигналів на класи, при цьому ні кількість, ні ознаки класів заздалегідь не відомі.

- Прогнозування. Даний тип задач, на думку авторів, може бути використано при роботі ICППР в цілому, оскільки здатні до узагальнення і виділення прихованих залежностей між вхідними та вихідними даними.

- Апроксимація. Нейронна мережа здатна апроксимувати будь-яку безперервну функцію 3 деякої наперед заданою точністю.

- Стиснення даних і асоціативна пам'ять. Даний тип задач може бути використано при організації роботи підсистеми формування сховища даних оскільки виявляє взаємозв'язки між різними параметрами надає можливість представити дані більш компактно, якщо дані тісно пов'язані між собою.

Отже, виходячи з зазначеного вище, сучасні ІСППР при проектуванні та розробці ії окреміх складових, в тій чи іншій мірі, можуть використовувати програмно-апаратний комплекс НМ.

Для вирішення задачі побудови ІСППР ,чи моделювання ідентифікації КЦ, на думку авторів, можє бути розглянуто і використано існуюче програмне забезпечення [9]: Alyuda NeuroIntelligence, Amygdala, Annie, Artificial Intelligence Recurrent Asymmetric Networks (NARIA), Cortex, DELVE, EasyNN, ECANSE, FANN, Fann Neural Network for Mathematica, Genesis, Java library, Joone (Java Object Oriented Neural Engine), libF2N2, Lightweight Neural Network ++, LTF-Cimulator, Netlab, NetMaker, Neurak, Neural Network Framework, Neural Network Leaves Recognition, Neural Network Models in Excel, Neural Network Toolbox for MATLAB, Neural Networks at your Fingertips, NeuralWorks- Professional II / PLUS, NeuroBox-dotNET, Neuromat, NeuroMine, Neuropilot Project, NeuroShell Predictor, NeuroSolutions, NeuroXL, NNSYSID Toolbox, Penguinwerks, Pythia, Simbrain, Temporal Difference Learning Project, Tiberius, Torch, Tradecision, Xerion, Neuroph, University of Hertfordshire Neural Network Software.

Слід зазначити, що програмне забезпечення (ПЗ) в списку представляє собою інструменти різного типу і призначення: середовища розробки, нейромережеві фреймворки, нейромережеві бібліотеки або симулятори. Таким чином, певне ПЗ призначене для вирішення відповідних завдань i не завжди чи не повною мірою задовольнятиме саме задачі побудови ІСППР. На думку авторів, для розробки програмно-апаратного комплексу майбутньої ІСППР, особливу увагу слід приділити середовищам розробки та відповідним нейромереживим бібліотекам різних об'єктно-орієнтованих мов програмування високого рівня , наприклад, C\#, C++, Java, Python, Lua, тощо.

Вибір мови та середовища програмування в першу чергу залежить від компетентності та кваліфікації розробника та наявності для мови та середовища відповідних бібліотек.

Також існує ряд фреймворків саме для розробки та використання ШНМ, наприклад: Tensor Flow, Microsoft CNTK, Caffe, Theano, MXNet, Torch т.п. Наведені фреймворки мають як свої переваги так і недоліки $[10,11]$.

При проектуванні ІСППР на базі ШНМ, значну роль відіграє і тип НМ. Відповідно до принципів побудови НМ, мережа складається з шарів та обов'язково включає в себе перший (вхідний) 
шар нейронів, який не виконує перетворень і обчислень, він приймає та розподіляє вхідні сигнали по іншим нейронам. Далі в залежності від критеріїв класифікації, ШМН можуть бути одношаровими (більш простими) чи багатошаровими (більш складними).

Крім кількості шарів, нейронні мережі можна класифікувати по напрямку розподілу інформації по синапсах між нейронами: нейромережі прямого поширення (односпрямовані), рекурентні нейронні мережі (із зворотними зв'язками), радіально-базисні функції чи карти що самоорганізуються.

Щоб підкреслити велику кількість типів НМ, можна зазначити, що також можна класифікувати:

- в залежності від типів нейронів: однорідні, гібридні;

- В залежності від методу нейронних мереж з навчання: навчання з учителем, без вчителя, 3 підкріпленням;

- за типом вхідної інформації: аналогові, виконавчі, образні;

- за характером налаштування синапсів: 3 фіксованими зв'язками, динамічними зв'язками.

Також слід зазначити, що на теперішній час набули популярності та розповсюдження більше двох десятків типів мереж[12-13], що в свою чергу в черговий раз підкреслює складність та важливість адекватного вибору НМ.

Штучний нейрон (ШН) (рис. 1.) складається з синапсів, які пов'язують входи нейрона 3 ядром; ядра нейрона, що здійснює обробку вхідних сигналів і аксона, який пов'язує нейрон 3 нейронами наступного шару. Кожен синапс має вагу, який визначає, наскільки відповідний вхід нейрона впливає на його стан.

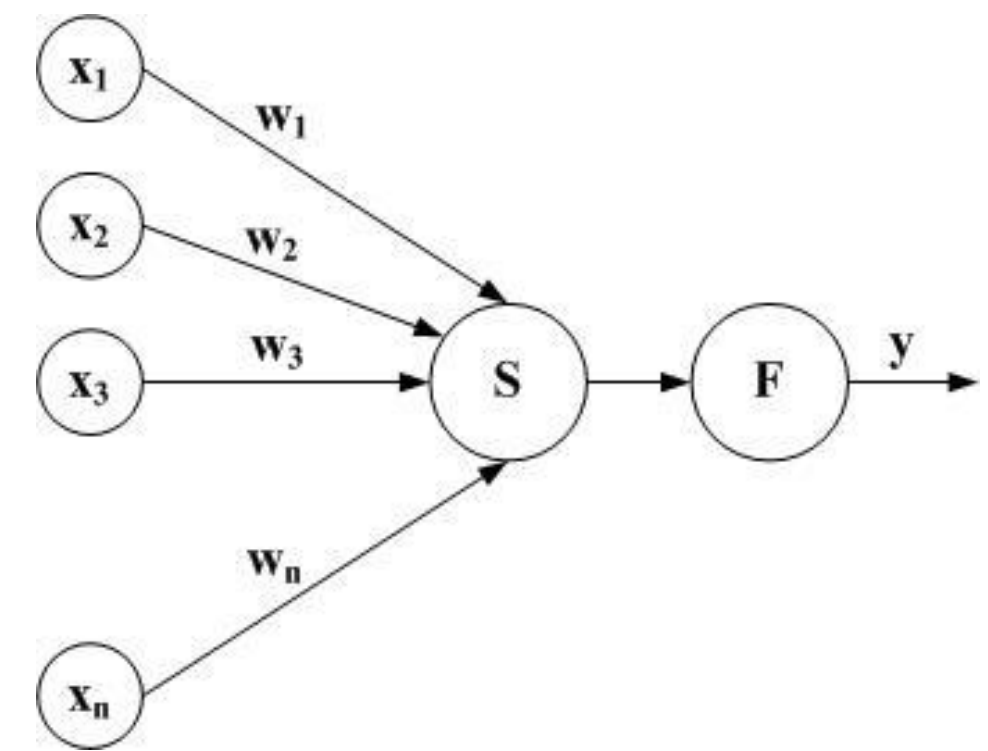

Рис. 1. Типова структура штучного нейрону

Стан нейрона визначається за формулами:

$$
\mathrm{S}=\sum_{\mathrm{i}=1}^{\mathrm{n}} \mathrm{x}_{\mathrm{i}} \mathrm{w}_{\mathrm{i}}
$$

$\mathrm{n}$ - число входів нейрону, $\mathrm{x}_{\mathrm{i}}$ - значення i-го входу нейрону, $\mathrm{w}_{\mathrm{i}}$ - вага i-го синапсу.

Далі сигнал $\mathrm{S}$ перетворюється активаційною (передавальною) функцією нейрона $\mathrm{F}$ у вихідний сигнал у. Математично це можна виразити формулою:

$$
\mathrm{y}=\mathrm{F}\left(\sum_{\mathrm{i}=1}^{\mathrm{n}} \mathrm{x}_{\mathrm{i}} \mathrm{w}_{\mathrm{i}}\right)
$$

Якщо проаналізувати типові структури ШН та НМ (Рис. 1-2.), не дивлячись на різноманіття сучасних ШНМ, можна зробити висновок, що головними їх параметрами $€$ тип, кількість вхідних ознак (якісні, кількісні) та їх значення для системи (вагові коефіцієнти).

Також, після аналізу різних типів НM, авторами зазначається, що різні типи НМ можуть бути використані в одній ІСППР при розробці її окремих підсистем [1-2], але також за умов визначення вхідних та вихідних сигналів. 


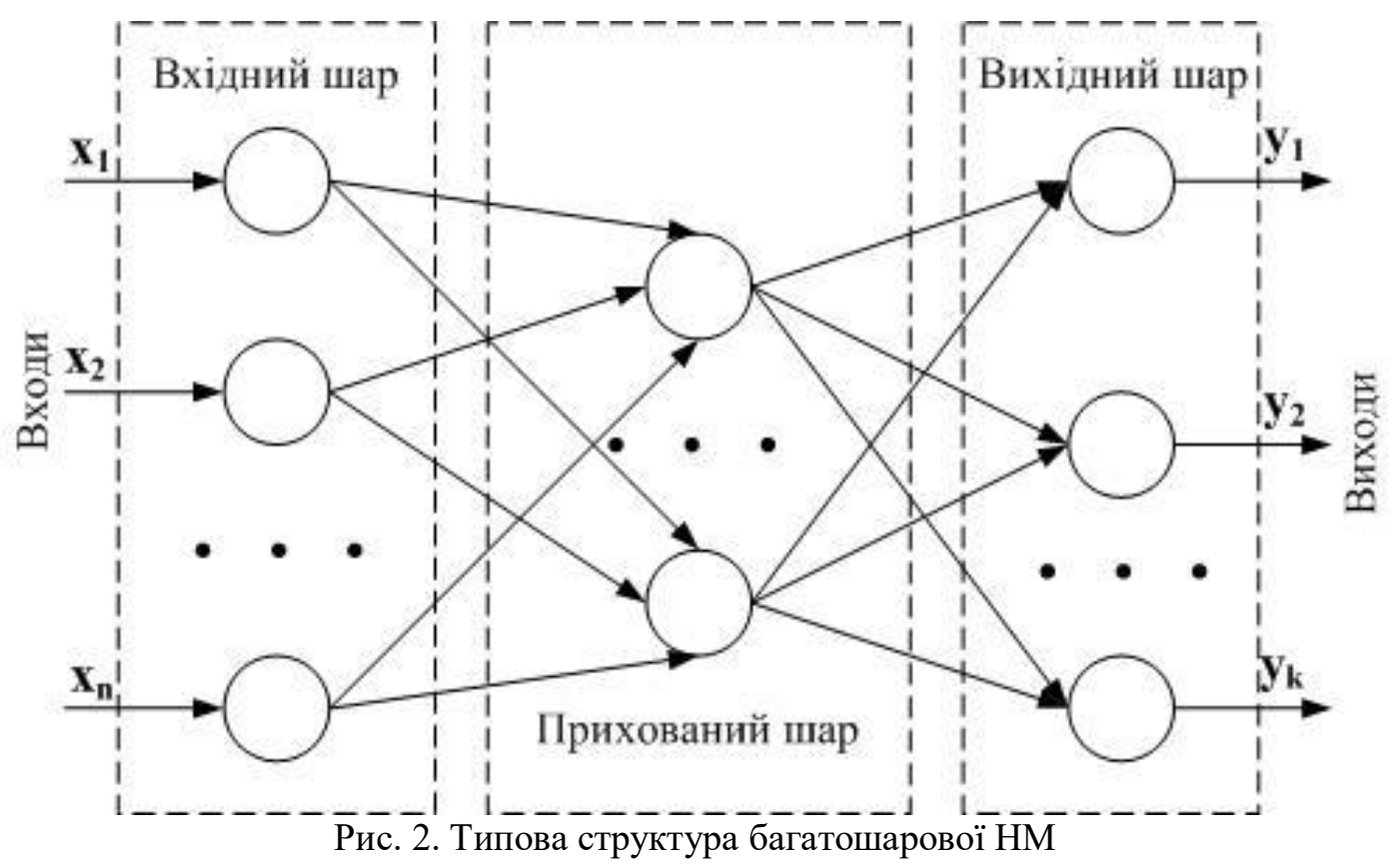

Таким чином, за думкою авторів, в комплексі повинна вирішуватися і задача обгрунтування $\mathrm{i}$ дослідження характеристик і властивостей самих ознак (вхідних параметрів).

У зв'язку з великою кількістю типів/видів об’єктів КЦ і при цьому кожен тип може бути описаний різними характеристиками (параметрами), рішення ідентифікації всіх об'єктів КЦ є завданням дуже складною і трудомісткою. Виходячи зі сказаного, для спрощення процесу моделювання (створення принципової схеми, моделі) авторами було прийнято рішення в подальших роботах сконцентрувати увагу та відпрацювати на прикладі ідентифікації та аналізі одного виду/типу КЦ - картин. Таким чином, перевірка на адекватність моделі (системи) може бути виконана на прикладі картин, і в подальшому поширена на інші типи об'єктів КЦ.

Висновки та перспективи подальшого дослідження. Авторами було проаналізовано проблеми, пов'язані з вибором сучасних методів та засобів побудови ІСППР ІКЦ, а також з рішеннями, які при цьому використовуються. Отримані результати дозволяють зробити наступні висновки:

- Проблемна галузь є душе широкою та не досить вивченою сферою досліджень.

- Вибір інструментів побудови сучасних ІСППР є комплексною задачею, де слід враховувати всі складові та елементи ІСППР.

- Визначення критеріїв для аналізу та ідентифікації (вхідні дані, ознаки об'єктів) при створенні ICППР для підтримки багатокритеріальних рішень у складному інформаційному середовищі впливає на вибір інструментів для побудови ІСППР.

- У даній статті, авторами висвітлена задача вибору й обгрунтування типової структури НС (обгрунтування діапазону кількості вхідних нейронів (параметрів), кількість шарів НС, типу НС, тощо) і їі властивостей.

- В роботі автори наводять аналітичний огляд НМ можливих до застосування для моделювання залежності підтримує рішення (відповіді системи на запит) від вхідних ознак (параметрів переданих системі для обробки і аналізу).

Також слід зазначити, що для вирішення окремих питань, наприклад, для обгрунтування критеріїв для аналізу та ідентифікації об’єктів КЦ, слід залучати відповідних фахівців в галузі мистецтвознавства, чи звертатися до нормативно-правових документів в галузі роботи в зазначеній галузі, й можуть розглядатися в окремих роботах.

\section{Список бібліографічного опису}

1. Martynenko A., Moroz V., \& Nulina I. (2020). An intelligent decision support system for cultural property identification. COMPUTER-INTEGRATED TECHNOLOGIES: EDUCATION, SCIENCE, PRODUCTION, (39), 78-82. http://citjournal.com.ua/index.php/cit/article/view/126

2. MartynenkoA., MorozB., HulinaI., \& SyrotkinaO. (2020). Conceptual model of an intelligent decision support system to identify cultural values. COMPUTER-INTEGRATED TECHNOLOGIES: EDUCATION, SCIENCE, PRODUCTION, (40), 51-57. http://cit-journal.com.ua/index.php/cit/article/view/156

3. Martynenko A., Moroz B., Gulina I. "Intelligent decision support system for the identification of cultural values". IV AllUkrainian scientific-practical conference "Prospective areas of modern electronics, information and computer systems (MEICS2019)”. Dnipro, November 27-29, 2019 http://meics.dnure.dp.ua/files/MEICS-2019.pdf

() Мартиненко А.А., Мороз Б.І., Гуліна І.Г. 


\section{Луцььк, 2020. Випуск № 41}

4. Комарцова Л.Г. «Методы и модели в системах поддержки принятия решений на начальном этапе проектирования распределенных вычислительных систем» [Електронний ресурс] // Режим доступу: http://www.ict.nsc.ru/ws/Lyap2001/2250/index.html\#ft

5. Хайкин С. Нейронные сети. Полный курс 2-е изд. Пер. с англ. - М.: Издательский дом "Вильямс", 2006. - 1104 с.

6. Рутковская Д., Пилиньский М., Рутковский Л. «Нейронные сети, генетические алгоритмы и нечеткие системы» 2 е изд., стереотип. 2013. - 384 с.

7. Бодянский Е.В., Руденко О.Г. «Искусственные нейронные сети: архитектуры, обучение, применения». Харьков: Телетех, 2004. - 369 c.

8. Искусственные нейронные сети (ИНС) [Електронний ресурс] // Режим доступу: https://www.it.ua/ru/knowledgebase/technology-innovation/iskusstvennye-nejronnye-seti-ins

9. Нейросетевое программное обеспечение [Електронний ресурс] // Режим доступу: https://bookflow.ru/nejrosetevoeprogrammnoe-obespechenie

10. И.В. ИльИн, К.В. Гудков АНАЛИЗ ПРОГРАММНЫХ СРЕДСТВ ДЛЯ ГЛУБИННОГО ОБУЧЕНИЯ ИСКУССТВЕННЫХ НЕЙРОННЫХ СЕТЕЙ [Електронний ресурс] // Режим доступу: http://www.penzgtu.ru/fileadmin/filemounts/confcit/articles/spring_2018/04.pdf

11. Top 9 Frameworks in the AI World [Електронний ресурс] // Режим доступу: https://geekflare.com/ai-frameworks/

12. А. Павленко. Типы нейронных сетей. Принцип их работы и сфера применения [Електронний ресурс] // Режим доступу:https://otus.ru/nest/post/1263/

13. Нейронные сети. [Електронний ресурс] // Режим доступу: http://wiki.mvtom.ru/index.php

\section{References}

1. Martynenko A., Moroz V., \& Nulina I. (2020). An intelligent decision support system for cultural property identification. COMPUTER-INTEGRATED TECHNOLOGIES: EDUCATION, SCIENCE, PRODUCTION, (39), 78-82. http://citjournal.com.ua/index.php/cit/article/view/126

2. Martynenko A., Moroz B., Hulina I., \& Syrotkina O. (2020). Conceptual model of an intelligent decision support system to identify cultural values. COMPUTER-INTEGRATED TECHNOLOGIES: EDUCATION, SCIENCE, PRODUCTION, (40), 51-57. http://cit-journal.com.ua/index.php/cit/article/view/156

3. Martynenko A., Moroz B., Gulina I. "Intelligent decision support system for the identification of cultural values". IV AllUkrainian scientific-practical conference "Prospective areas of modern electronics, information and computer systems (MEICS2019)". Dnipro, November 27-29, 2019 http://meics.dnure.dp.ua/files/MEICS-2019.pdf

4. Komartsova L.G. "Methods and models in decision support systems at the initial stage of design of distributed computing systems" [Electronic resource] // Access mode: http://www.ict.nsc.ru/ws/Lyap2001/2250/index.html\#ft

5. Haykin S. Neural networks. Complete course 2nd ed. Per. from English. - M.: Publishing house "Williams", 2006. - 1104 p.

6. Rutkovskaya D., Pilinsky M., Rutkovsky L. "Neural networks, genetic algorithms and fuzzy systems" 2nd ed., Stereotype. 2013.- 384 p.

7. Bodyansky E.V., Rudenko O.G. Artificial Neural Networks: Architectures, Learning, Applications. Kharkov: Teletekh, 2004. - 369 p.

8. Artificial neural networks (ANN) [Electronic resource] // Access mode: https://www.it.ua/ru/knowledge-base/technologyinnovation/iskusstvennye-nejronnye-seti-ins

9. Neural network software [Electronic resource] // Access mode: https://bookflow.ru/nejrosetevoe-programmnoeobespechenie

10. I.V. Ilyin, K.V. Gudkov ANALYSIS OF SOFTWARE FOR DEEP LEARNING OF ARTIFICIAL NEURAL NETWORKS [Electronic resource] // Access mode: http://www.penzgtu.ru/fileadmin/filemounts/confcit/articles/spring_2018/04.pdf

11. Top 9 Frameworks in the AI World [Electronic resource] // Access mode: https://geekflare.com/ai-frameworks/

12. A. Pavlenko. Types of neural networks. The principle of their operation and scope [Electronic resource] // Access mode: https: //otus.ru/nest/post/1263/

13. Neural networks [Electronic resource] // Access mode: http://wiki.mvtom.ru/index.php 